\title{
Practical implications for utilizing more approach shots in match situations
}

\author{
Hadi Darvishomrani (AUS)
}

ITF Coaching and Sport Science Review 2017; 71 (25): 6 - 8

\begin{abstract}
Wanting to win a tournament increases the stress on all athletes. Ability of utilizing different strategies in sports, specially under match-situation's pressure, is important. Changing the rhythm of game (e.g. moving from baseline to service line) can be one of these strategies. Approaching to the net could be very useful among junior tennis players, although not many of junior tennis players do not use this tactic when they have to do it. This article mentions some reasons and implications for approaching to the net during a match play.
\end{abstract}

Key words: approach shot, volley, psychology, strategy Received: 25 Oct 2016 Accepted: 30 Jan 2016 Corresponding author: Alistair Higham Email: alistair.higham@lta.org.uk

\section{INTRODUCTION}

One of the biggest problems of tennis coaches and psychologists is their capability to have effective communications with tennis players in order to improve their performance in specific situations. Frequently, sport psychologists have no idea about tennis and its mental requirement; neither can tennis coaches understand sport psychologists' scientific language. One of the most useful winning tactics in tennis is hitting an approach shot and taking the point with volleys or overhead. Yet, most junior tennis players do not use this tactic because of some technical, tactical, and psychological issues. This present paper describes some psychological reasons of not approaching to the net in tennis, and some implications for tennis coaches and tennis players in order to use this tactic for winning a point in a match. All top junior players have good forehands, backhands, and technically right volleys. Some of them are not going for approach shots and hitting volleys, they are hitting deep shots and trying to force their opponents to make the error. If the opponents' passing shot is coming towards them, they are fearful of the ball that result in either just pass the ball over the net without any targets, or loosing the point by receiving a passing shot. This paper is trying to mention some reasons and solutions for this issue, and mentions some practical implication for coaches.

\section{PSYCHOLOGICAL ISSUES}

Lack of self-confidence

One of the most effective psychological factors that are associated with performance for many sports is self-confidence (Taylor, 1995). Tennis is a sport needing precise and accurate movements with a long duration and lots of short bursts. Therefore, maintaining and increasing self-confidence is one of the most important targets in tennis. The first way of acquiring self-confidence is to educate tennis players to understand their thoughts and to control it during stressful competitive situations (Mamassis \& Doganis, 2010). For increasing selfconfidence, using positive key words, positive self- talk, positive body language, and imagery techniques are very useful (Taylor, 1995). Mental Training Program (MTP) is one of the most useful techniques for improving self-confidence in individual's mental needs (Savoy \& Beitel, 1997).

Motivational and visual imagery are predictor of selfconfidence and somatic state anxiety respectively. Moreover, there is correlation between better performance and positive self-talk (Mamassis \& Doganis, 2010). Mamassis and Doganis (2010), found that there is a development in the intensity of self-confidence and perceived performance for each of the MTP group athletes.

Finally, the intensity of self-confidence affects directly on the success of winner shots in approaching the net. Having high self- confidence in tennis players lead them to play aggressive when it is possible, and also ensuring that they can win the point by approach shots helps them to use this tactic for winning.

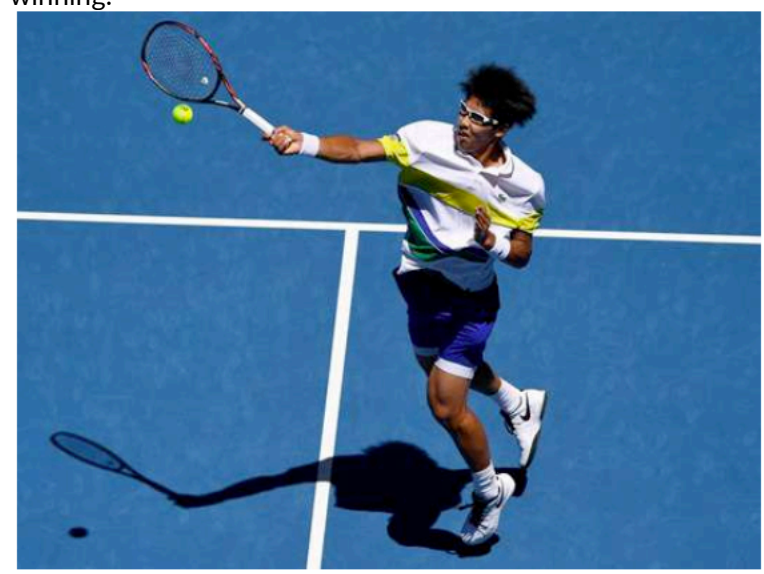

Fear of failure

Most of the noticeably counterproductive emotional reactions during tennis events are stemmed from unconscious fears of failure. Human nervous systems were not created to apply motor control under stress for long duration. There are a lot of examples of unforced errors in top tennis players, while an amateur tennis player could get the point. Experiencing missing shots of easy balls result in feeling fear of failure. Therefore, negative psychological aspects affect on tennis players to make errors when they are approaching to net.

Fear of failure usually comes from thinking about outcomebased results as against performance-based results. Fear of failure is considerably related to performance-avoidance and performance- approach achievement goals (Conroy \& Elliot, 2004). 
Fear of experiencing failure in approach shots is strongly related to performance-avoidance. Fear of failure seems to activate behavior and influences individuals toward the intention of avoidance achievement goals (Conroy \& Elliot, 2004).

\section{Effects of anxiety}

Depending on upon different sport situations, anxiety might be a useful or useless emotion. In tennis, anxiety could motivate tennis players to practice hard in order to play better tennis. However, in some situations it might become useless that can be considered as signals of failure (van Dinther, Dochy, \& Segers, 2011). In the past studies have predominantly focused on emotions relating to achievement outcomes (e.g. test anxiety, Zeidner, 1998, 2007) as well as emotions following success and failure (e.g. Weiner, 1985). However studies have largely disregarded activity related achievement emotions (Pekrun, 2006; Pekrun, Elliot, \& Maier, 2006; Pekrun, Hall, Goetz, \& Perry, 2014). Pekrun (2006) argues that emotions experienced during achievement-related activities can also be seen as achievement emotions. If tennis players reach success at approach shots in their practice time, they would utilize anxiety in a positive way.

According to research, the control-value theory assumes that negative activating emotions such as anxiety and intrinsic motivation. Failure-related anxiety can reduces a player's intrinsic motivation while at the same time triggering extrinsic motivation to invest effort when success is favorable in order to prevent failure (Linnenbrink \& Pintrich, 2002; Pekrun, 2006). Finally, in order to utilize this emotion to improve tennis players' optimal performance level, it is vital to distinguish between useful and useless anxiety. Useless anxiety in the form of negative emotions and thoughts, which impede performance, should be intelligibly recognized before they become seriously hindered and opposed to change. Tennis players should increase a set of adaptable routines that they can apply in different game situations, as well as practice implements helpful thoughts to decrease anxiolytic effects.

Practical implication for coaches

- Introducing and applying mindset method to your students to get familiar with their mental abilities.

- Keep referring to match play as much as possible when practicing approach shots in close drills (Reynolds, 2013).

- Tell your students write their goals down. This crystallizes them and gives them more force (e.g., I will like approaching to the net, but only after I have hit solid groundstrokes, which have got my opponent out of the court).

- Teaching your students how to regulate their anxiety and to adopt a season-long goal setting procedure (Mamassis \& Doganis, 2010).

- Help your student to trust in their abilities by underlining their strengths before an event, because of some positive effects on self-confidence and performance during the match (Mamassis \& Doganis, 2010).

- Utilizing imagery techniques in practice sessions.

- Practice more approach shots in practice sessions, and apply it in game situations.

- Writing and promising some sentences give tennis players more motivation for utilizing as many approach shots as they can. Sentences such as:

1. My volleys will be easy but I will have learned how to hit the ball short down the line with them.
2. I will win 1 point at each game at least with approach shot.

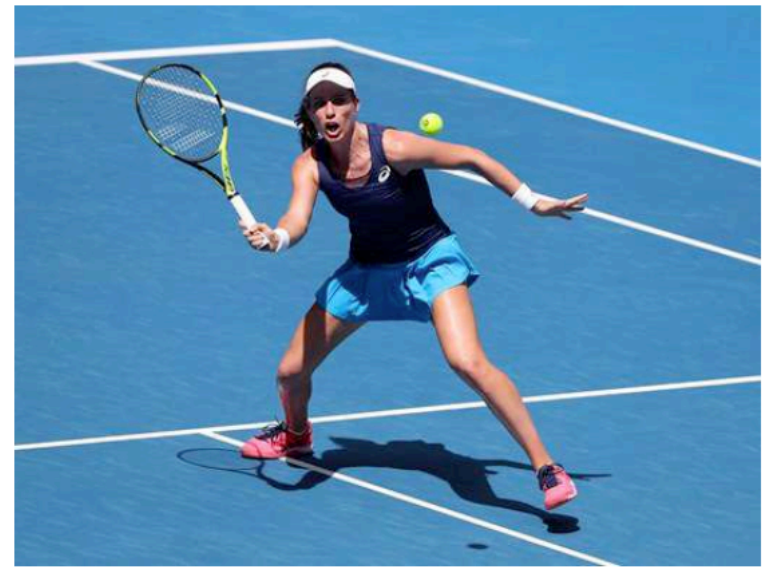

\section{CONCLUSION}

Utilizing different tactics and strategies in tennis are so important. Lack of self-confidence, fear of failure, anxiety during a match, weaknesses of net play, personality of players, weaknesses of footwork, and different aspects of psychology can avoid the junior tennis players to approach to the net when they have to. In modern tennis, changing the rhythm of the game is one of the significant strategies that players can win a point with.

\section{REFERENCES:}

Conroy, D. E., \& Elliot, A. J. (2004). Fear of failure and achievement goals in sport: addressing the issue of the chicken and the egg. Anxiety, stress and coping, 17(3), 271285.https://doi.org/10.1080/1061580042000191 642

Davids, K. W., Button, C., \& Bennett, S. J. (2008). Dynamics of skill acquisition: A constraints-led approach: Human Kinetics.

Dekkers, H., \& Reardon, J. (2010). A guide to a new mentality: Mindset in a nutshell. ITF Coaching and sport science review, 18(52), 19-20.

Linnenbrink, E. A., \& Pintrich, P. R. (2002). Achievement goal theory and affect: An asymmetrical bidirectional model. Educational Psychologist, 37(2), 6978.https://doi.org/10.1207/S15326985EP3702_2

Mamassis, G., \& Doganis, G. (2010). The Effects of a Mental Training Program on Juniors Pre-Competitive Anxiety, Self-Confidence, and Tennis Performance. Journal of applied sport psychology, 16(2), 118137.https://doi.org/10.1080/1041320049043790 3

Pekrun, R. (2006). The control-value theory of achievement emotions: Assumptions, corollaries, and implications for educational research and practice. Educational psychology review, 18(4), 315341.https://doi.org/10.1007/s10648-006-9029-9

Pekrun, R., Elliot, A. J., \& Maier, M. A. (2006). Achievement goals and discrete achievement emotions: A theoretical model and prospective test. Journal of educational Psychology, 98(3), 583.https://doi.org/10.1037/0022-0663.98.3.583

Pekrun, R., Hall, N. C., Goetz, T., \& Perry, R. P. (2014). Boredom and academic achievement: Testing a model of reciprocal causation. Journal of educational Psychology, 106(3), 
Reynolds, K. (2013). Improving performance ITF Coaching \& sport science review, 21(60), 19-20.

Savoy, C., \& Beitel, C. (1997). The relative effect of a group and group/individualized program on state anxiety and state self- confidence. Journal of Sport Behavior, 20(3), 364-376.

Sanderson, J., Weathers, M., Snedaker, K., \& Gramlich, K. (2016). "I Was Able to Still Do My Job on the Field and Keep Playing" An Investigation of Female and Male Athletes' Experiences With (Not) Reporting Concussions. Communication Sport.https://doi.org/10.1177/216747951562345 5

Taylor, J. (1995). Aconceptual model for integrating athletes' needs and sport demands in the development of competitive mental preparation strategies. The Sport Psychologist, 9 , $339-$ 357.https://doi.org/10.1123/tsp.9.3.339

Van Dinther, M., Dochy, F., \& Segers, M. (2011). Factors affecting students' self-efficacy in higher education. Educational Research Review, 6(2), 95108.https://doi.org/10.1016/j.edurev.2010.10.003
Zeidner, M. (1998). Test anxiety: The state of the art. New York: Plenum.

RECOMMENDED ITF TENNIS ACADEMY CONTENT (CLICK BELOW)

\section{ITF Academy}

Copyright (c) Hadi Darvishomrani 2016

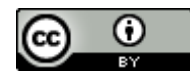

This text is under a Creative Commons BY 4.0 license

You are free to Share - copy and redistribute the material in any medium or format - and Adapt the content - remix, transform, and build upon the material for any purpose, even commercially under the following terms:

Attribution: You must give appropriate credit, provide a link to the license, and indicate if changes were made. You may do so in any reasonable manner, but not in any way that suggests the licensor endorses you or your use.

CCBY 4.0 license terms summary $\quad$ CCBY 4.0 license terms 